\title{
Knowledge and Synthesis Gaps in Men's Health: Type 2 Diabetes and Depression in Northern British Columbia, Canada
}

\author{
Mamdouh M. Shubair ", Meck Chongo, Jamie Reschny \\ School of Health Sciences, University of Northern British Columbia, 3333 University Way, Prince George, BC, V2N 4Z9 \\ *Corresponding Author: mamdouh.shubair@unbc.ca
}

Copyright (C) 2014 Horizon Research Publishing All rights reserved.

\begin{abstract}
The workplace is notable as an optimal setting for health promotion programs. The workplace offers a natural convenient environment to support the promotion of health and wellness of workers in organizations. Adult men (18 years of age or over) in natural resource industries who work full-time spend more of their waking hours at work, away from their families due to shift work, hectic hours, and busy lifestyles. The workplace setting can therefore be harnessed to offer workers frequent and sustained exposure to effective interventions during prime hours. The purpose of this Scopus review paper is to assess the magnitude of type 2 diabetes (T2D) and depression among working men in resource-based occupations (trucking; logging; mining; oil and gas; and forestry). The paper proposes a settings-based workplace health promotion (WHP) framework to be adapted from a community-based perspective. We argue the proposed framework can be applied to effect individual worker's lifestyle behaviours, and from a socio-ecological perspective to influence organizational change and health policy. We propose WHP programs for men recognizing that gender has an important role in influencing one's lifestyle and overall health. From a socio-ecological perspective, the environment also plays a pivotal role in affecting lifestyle choices by supporting or hindering behaviours that occur in 'settings' such as family, school, workplace, or community environments. While arguing for WHP interventions, the paper recognizes the importance of upstream policy initiatives that should enhance and cultivate such interventions at organizational and community levels.
\end{abstract}

Keywords Health Promotion and Disease Prevention, Men's Health Interventions, Depression, Diabetes, Epidemiology of Men's Health

\section{Introduction}

It is recognized that people in developed countries are, in general, becoming less physically active and more poorly nourished. Physical inactivity and long bouts of sedentary behaviour have emerged as public health concerns associated with unhealthy lifestyles and obesity ${ }^{18}$. Obesity rates have risen to epidemic proportions globally to an extent that they are recognized as a public health crisis ${ }^{1,23}$. Moreover, there is evidence that working adults with higher occupational sitting time do not necessarily compensate for their sitting at work by spending less time in sedentary behaviours during leisure time ${ }^{18}$. Estimates of the global burden of disease attributable to such unhealthy behaviours and nutrition-related risk factors report increased risk of adverse health conditions such as cardiovascular disease (CVD), type 2 diabetes (T2D) and other chronic conditions ${ }^{29,33,60}$. This demonstrates that the comorbid conditions are the leading causes of millions of deaths ${ }^{30,36}$. In the work environment, the behaviours, nutritional risk factors, and the resultant chronic conditions increase labour costs not only through direct health care costs, but also through indirect costs incurred due to productivity loss from missed work, ineffectiveness on-the-job (i.e., presenteeism), and turnover when an employee is unable to return to work because of disability or illness ${ }^{15}$.

Unhealthy employees account for a significant economic burden estimated to billions annually ${ }^{33,60}$. Physical inactivity alone, for example, represents an economic burden for Canada estimated at $\$ 6$ billion due to direct and indirect healthcare costs ${ }^{23}$. Depending on the occupational setting, nature of the job and other factors such as age and job experience, workers commonly have risk behaviours, miss preventive care. In addition, inadequate health and safety skills training are a problem particularly for workers with low incomes. Furthermore, as there is currently a demographic shift in the age and gender distribution of the workforce in Canada, the United States of America (USA), Australia, New Zealand, and Europe, the prevalence of chronic conditions including illness, injury, disability, and death will continue to rise as the baby boomers and the overall workforce age ${ }^{10}$. 
As a result of these daunting disease trends and demographics, employers have not succeeded in lowering health care costs through containment strategies ${ }^{32}$. Employers have thus been prompted to seek health promotion interventions that are both appropriate and cost-effective ${ }^{19}$. Recent studies suggest that management of lifestyle factors, such as stress and lack of physical activity, impact cardio-metabolic conditions adversely ${ }^{23,29,30}$. Efforts to reduce obesity rates have thus largely focused on nutrition and regular physical activity ${ }^{29}$. However, despite the known health benefits of physical activity, most Canadian adults do not perform enough physical activity to achieve health and well-being benefits ${ }^{20}$.

In Canada, many rural communities are dependent on natural resource industries development. Natural resource development has played an integral role in determining the social, economic and political landscape in Canada, and has played an integral role in shaping the rural Canadian economy. In parallel, socioeconomic and health challenges faced by rural Canadian communities are increasingly being recognized as higher morbidity and mortality rates for chronic conditions such as diabetes, depression, and other health outcomes in comparison to urban Canadian communities $^{51}$.

The objective of this paper is to argue for male workers in resource-dependent occupations, primarily trucking, logging, mining, oil and gas, and forestry, in northern British Columbia (BC) while proposing a settings-based conceptual framework to implementing WHP in the contexts within which such men live and work. We propose WHP programs for men recognizing that gender has an important role in influencing one's behaviour, lifestyle and overall healt ${ }^{26}$.

From a socio-ecological perspective, the environment also plays an important role in influencing lifestyle behaviours (such as healthy eating and active living) by supporting or hindering behaviours that occur in 'settings' such as family, school, or community environments ${ }^{53}$. We recognize other determinants of health that influence behaviours, while arguing for WHP interventions in northern $\mathrm{BC}$ in the management of T2D in natural-resource industry workers ${ }^{43}$.

\section{Methods}

A systematic literature search was conducted to identify men's health research in northern BC and elsewhere in Canada. Keywords used in the search include: men's health, workplace, health promotion, absenteeism, type 2 diabetes, disability, and effectiveness. This Scopus review paper was an inclusive search for Men's Health to identify community-based programs, interventions and/or strategies related to worker's health, industry-related productivity and factors which affect such productivity.

\subsection{Rationale for T2D}

Type 2 Diabetes (T2D) is a chronic condition that occurs when the pancreas does not produce enough insulin to meet the body's needs and/or the body is unable to respond properly to the actions of insulin13. Currently diabetes is treated with diet and exercise measures, diabetes medications (anti-hyperglycemic agents), and/or insulin as there is no cure for the disease14. Type 2 diabetes (T2D) is a growing public health concern in Canada and abroad, that poses significant challenges for researchers, planners, and practitioners 2,40 , as the number of at-risk individuals, middle - aged and older, expands the prevalence of this condition42. On a global level, T2D is projected to impact 300 million by the year 20252. According to the Canadian Diabetes Association (CDA), currently, one in four Canadians have diabetes; making up over two million Canadians overall12.Canadians' future risk of developing diabetes is estimated to rise to one-in-three individuals by 202013. Concentrations of people in the province of BC carry a higher than national average risk of developing T2D12. These include marginalized and underserved populations of Aboriginal peoples, immigrants, some ethno-cultural communities, and low-income Canadians 13. Furthermore, the ability to manage diabetes for communities in northern $\mathrm{BC}$ is impacted by geographic location. There is meagre access to diabetes medications, devices, supplies, health care professionals, and programs and services 13,43.

Obesity, lack of physical activity, and having an unhealthy diet has been shown to be the strongest predictors of T2D40. Up to $90 \%$ of significant deterioration of glycemic control and the resulting T2Dare related to obesity2,40. These factors, combined with the fact that Canada has a growing and aging population, of which over $60 \%$ are overweight or obese, continue to drive the high prevalence rates of diabetes14.Canada's future prosperity and the sustainability of its healthcare system are threatened by the rising costs of diabetes management. Diabetes cost Canada $\$ 11.7$ billion in 2010 , and this is projected to rise to $\$ 16$ billion by 202014 . In British Columbia (BC) alone, it is estimated that by 2020 the diabetes prevalence rate will have grown to $10.3 \%$ (from $7.4 \%$ in 2010 ), and the cost of managing diabetes to $\$ 1.9$ billion (from $\$ 1.3$ billion in 2010)14.In the work environment, the financial cost of a diabetic worker to an employer can be as much as five times that of workers without diabetes11. Living

a healthy lifestyle, and implementation of comprehensive WHP strategies, can have the potential to reduce the annual cost of managing diabetes in Canada14.

Over the past decade, Canada has made progress in the management of T2D. Through the Canadian Diabetes Strategy, several new jurisdictions have invested in research to develop tools and services to help people with diabetes effectively self-manage their disease. This includes support for both an Aboriginal Diabetes Initiative from the 2010 Federal Budget13and various organizations working with communities at high risk of developing $\mathrm{T} 2 \mathrm{D}$ and its complication43. In British Columbia (BC), diabetes management is now identified as a priority and diabetes care guidelines have been produced13. Furthermore, a healthy 
living initiative called Act Now is in place to help reduce the impact of diabetes through focus on healthy eating and physical activity13. Critical education for effective diabetes self-management is not uniform across jurisdictions and across Canada, and accessible information about supports provided through best practices for diabetes services is lacking13. There is thus a clear and growing need for managing T2D in Canada through investments in WHP programs 12 . This would be in line with current evidence that indicates diabetes care delivered in such programs is effective in improving health outcomes for individuals12,23.

Diabetic outcomes can be improved effectively through lifestyle change strategies that combine dietary changes and physical activity40. Physical activity plays a key primary role among those groups most at - risk and in the management of T2D2, particularly glycemic control and improvements in cardiovascular risk profile, such as decreased hyperinsulinemia, increased insulin sensitivity, reduced body fat, and reduction in complications (heart disease, kidney disease, adult blindness and amputation)and premature death 40,43 . These measures have been reported to be effective for middle - aged adults, representing active working age adults that will contribute the greatest number of future incident cases of T2Din Canada2. There is hope therefore in that, by promoting self-management through WHP programs, T2Dcan be managed effectively, its complications prevented 12 , and mortality reduced allowing people with diabetes to live long and healthy lives14. The financial burden of diabetes can also be reduced through WHP programs. For example, a $2 \%$ reduction in prevalence rates would have a $9 \%$ reduction in direct healthcare costs 14 .

In Canada in 2009-2010, males were significantly more likely to be overweight/obese than females. Among males, the prevalence of T2D among obese individuals is three times higher than those who are of normal weight 43 . Furthermore, between 2003 and 2010 Canadian males consumed less fruit and vegetables than females. Almost two-thirds of males did not meet healthy dietary recommendations 43. Consequently, more men than women have diabetes14. What is worse is that, throughout their life course, men tend to access health care services less frequently than women. Being primary income earners in families, men are highly stressed and fearful of taking time off work for chronic conditions such as T2D. Often by the time they do seek medical care, their T2D would have progressed with associated comorbidities (such as hypertension, high blood lipids). The life expectancy for northern $\mathrm{BC}$ men is shorter than their male counterparts in other urban/suburban regions of Canada6. Specifically, workers in the trucking, mining, forestry, and commercial transport sectors are responsible for $65 \%$ of the total deaths 5 .

\subsection{The link between T2D and Depression}

Just as T2D is common in Canada, so are mental health conditions ${ }^{43}$. In this context, depression, like T2D, affects one's capacity to work. A significantly high number of persons with depression either suffer serious challenges in daily life, are absent from work or identify reduced productivity ${ }^{16}$. Depression and T2D are common co-existent conditions from incidence to mortality ${ }^{17,35}$. The relationship between them has, however, been described as bi-directional; T2Dis associated with increased risk of depression and vice versa $^{17,35}$. Depression is more common among individuals with T2D than among those without ${ }^{24,43}$. The prevalence of depression among those who are physically inactive and have T2D is high ${ }^{24,35}$. Type 2 Diabetes (T2D) may increase the risk of depression because of the negative impact of receiving and having to cope with the diagnosis, and the worry of potentially developing debilitating complications and having to live a lesser quality of life. Conversely, depressive symptoms are associated with worsening blood glucose levels and T2D complications ${ }^{17}$.

The increased risk of T2D for those living with depression is attributed to obesity and negative health behaviours, such as physical inactivity and unhealthy eating ${ }^{39,43}$. However, this association is only partially explained by adjustment for these factors ${ }^{17}$. Depression also results in activation of several integrated biological systems that enhance insulin resistance and lead to T2D development, or worsen glycemic and metabolic outcomes in T2D patients ${ }^{35,39}$. Numerous studies have suggested the association of depression, and diabetes, with: (a) deregulated and overactive hypothalamic-pituitary-adrenal (HPA) activity, leading to changes in diurnal cortisol levels ${ }^{8}$; (b) a shift in sympathetic nervous system (SNS) tone toward enhanced sympathetic activity, leading to release of catecholamines ${ }^{17}$; and (c) a pro-inflammatory state associated with release of interleukin-6 (IL-6) ${ }^{9}$. Elovainio and colleagues ${ }^{25}$ also found that men with higher depression scores reported a more significant increase in the inflammatory marker C-reactive protein (CRP) than women. Side effects of combinations of antidepressant medications have also been put forward as a reason for increased risk of T2D in those with depression. All these associations increase insulin resistance and may thus explain the predisposition for depressed individuals to develop T2 ${ }^{17}$.

Research has identified that compared with individuals who have T2D alone, those with comorbid depression have increased disease burden, greater symptom severity, increasing functional, financial, and behavioural costs (for example, poorer adherence to diet, exercise, and medications), increased work disability, and increased medical services use, with or without T2D complications ${ }^{35}$. Furthermore, an increased risk of early mortality has been found to be associated with both conditions at higher rates than either condition alone ${ }^{24}$. With respect to management, it has been demonstrated that dietary and physical activity lifestyle interventions are an effective approach for T2D self-management and treatment of depression. However, as part of WHP, physical activity interventions for T2D would also help reduce depression. Studies have shown that, participants in a physical activity intervention program have 
a decreased risk of developing clinically defined depression ${ }^{3}$, as well as low rates of depression relapse ${ }^{24}$. In fact, the anti-depressant effect of physical activity is said to equal that for interventions, such as cognitive behavioural therapy $(\mathrm{CBT})^{23,49}$. Conversely, patients with no depression and hence better psychosocial health, tend to maintain physical activity and fulfill other self-management roles better than those who remain untreated ${ }^{7,23}$. Other studies suggest that worksite social support, as adjunct therapy for depression, may promote physical activity, lead to reductions in obesity, and improve insulin sensitivity ${ }^{23,56}$. Physical activity, as a treatment for depression in patients with T2D or vice versa, may be very acceptable intervention strategy for patients as it improves depressive symptoms and contributes to T2D management ${ }^{24}$.

\section{Northern British Columbia Context}

In northern $\mathrm{BC}$, the economic and employment opportunities that exist for men and their families have been greatly determined by the relative prosperity of the resources sector. While resource sector jobs provide good benefits when things are "booming", northern BC communities have experienced the downside or "bust" as a consequence of the current economic recession. Men make up a high percentage of the workforce and are most exposed to long shift work hours (employed men spend an average of 8-10 hours/day at work), few vacations, and stresses from living apart from their families, poor diets, inactive living, financial and social stresses, and the likelihood of using illicit drugs and substance abuse ${ }^{61}$. Such issues are of particular importance in the current job climate as they can lead to physical, environmental and psychosocial hazards and risks.

In addition, the relationship between adverse working conditions and negative health outcomes in northern BC, displays a strong social class gradient with higher risk for accident and illness clustering in lower status occupations, indicating that working conditions contribute significantly to health inequities ${ }^{6}$.To compound the situation, higher rates of obesity have been found in rural populations, including those of northern $\mathrm{BC}$, than in urban populations in Canada ${ }^{43}$. At every age, the prevalence of T2D is higher among individuals who are overweight or obese. This is consistent with other literature that shows that sedentary lifestyles increase the risk for the development of obesity and T2D. Type 2 Diabetes (T2D) thus represents a growing burden to the health, welfare, and productivity of individuals in underserved urban and rural communities, as well as morbidity and premature mortality ${ }^{24}$.

\subsection{Rationale for T2D Interventions for Men in Northern British Columbia}

Very little is known about either the number or scope of WHP intervention studies that have focused on men's needs or how effective these studies have been at changing behaviour. The review suggests that few WHP interventions have reported data for men ${ }^{61}$. With regard to physical activity interventions, for example, most have failed to appeal to men. Consequently, uptake by male employees has typically been poor $^{58,61}$. A systematic review identified that participation levels in workplace health promotion interventions were typically below $50 \%$. In general, female workers had a higher participation rate than men ${ }^{46}$. A strong rural ideology exists in northern $\mathrm{BC}$ in regards to rural development. The image of wide open geographical spaces and an abundant natural landscape attract people to the region ${ }^{22}$. Northern BC provides an ideal non-congested widely dispersed geographical setting for men and their families to live, work, and play. The statistics in Canada confirm the global observation that men's health generally lags behind that of women, despite the apparent socio-economic advantages that men enjoy ${ }^{59}$. As illustrated in Figure 1, the prevalence of diabetes amongst northern $\mathrm{BC}$ men is higher than their female counterparts across different age groups in 2010/11. Men's health is rarely analyzed through the lens of gender despite the fact that a large body of health research indicates that men with comparable social disadvantages to women, experience worse health outcomes with respect to injury rates, disability, chronic diseases, and mortality. While there have been multiple reports and programs focused on women's health in northern $\mathrm{BC}$, there has been little consideration of men's health initiatives around the world. Northern BC and the Northern Health Authority (NHA) have been somewhat progressive in this new and evolving area of research (Men's Health). 


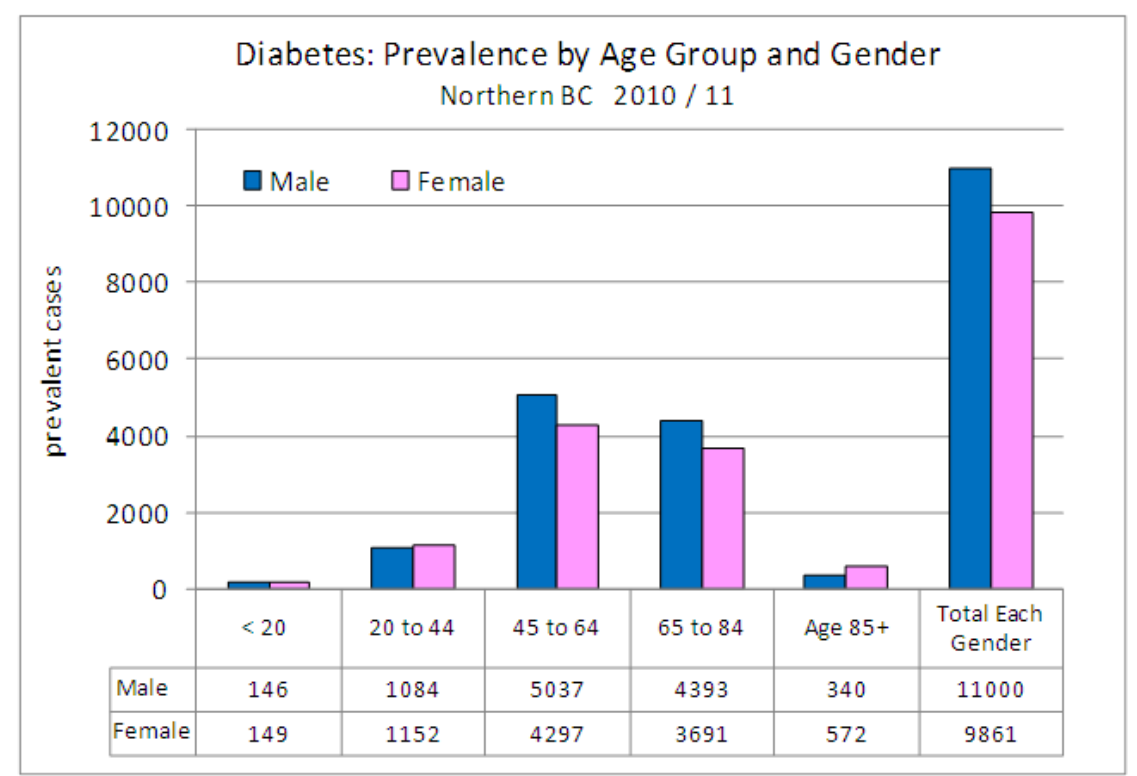

Data Source: BC Ministry of Health, Medical Services Economic Analysis Branch.

Chronic Conditions by incidence, prevalence, mortality and cost: 2001/02 - 2010/11: February 2012.

Acquired through Quantum Analyzer, January 2013

Contact: james.haggerstone@northernhealth.ca

Figure 1. Prevalence of Diabetes by Age group and gender, northern BC 2010/11

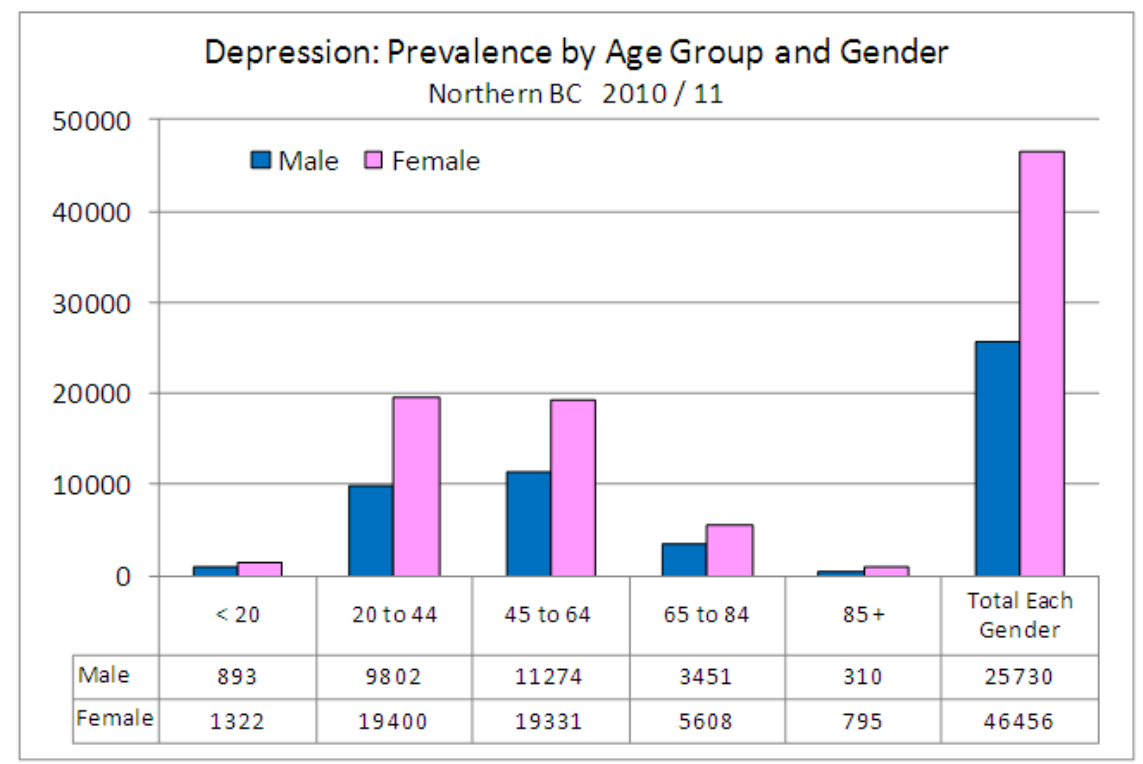

Data Source: BC Ministry of Health, Medical Services Economic Analysis Branch.

Chronic Conditions by incidence, prevalence, mortality and cost: 2001/02 - 2010/11: February 2012.

Acquired through Quantum Analyzer, January 2013

Contact: james.haggerstone@northernhealth.ca

Figure 2. Prevalence of Depression by Age group and gender, northern BC 2010/11

In a recent northern BC Men's Health study by Shubair and Gagne ${ }^{52}$, obesity was significantly associated with several cardiovascular (CV) risk factors. This finding has adverse health implications in terms of men's health. Having multiple risk factors puts these men at higher risk of mortality from CVD compared with individuals who only possess one risk factor ${ }^{31}$. Given the multifactorial nature of obesity and its associated comorbid conditions such as T2D,
WHP intervention strategies that target obesity are therefore warranted among men living and working in northern $\mathrm{BC}^{52}$. Employers in small workplaces, such as in northern $\mathrm{BC}$, might be able to reduce modifiable health risk behaviours among their workers by implementing evidence-based WHP best practices that target health-related policies, programs, and communication ${ }^{33}$. The case for addressing workplace health is therefore very strong and never more so than in the 
current economic climate. Investment in men's health at this stage and earlier can increase the years of productivity for a man, which benefits, families, the economy, and society at large.

Other factors that are increasingly common in the Canadian population include mental health conditions, such as depression and substance abuse which are important and warrant being mentioned, especially for WHP considerations in a northern $\mathrm{BC}$ resource industry context ${ }^{11}$. Depression, for example is highly prevalent with one in eight Canadians $(12.2 \%)$ reporting symptoms consistent with depression at some point during their lifetime ${ }^{43}$. Figure 2 demonstrates the prevalence of depression in both sexes across different age groups in 2010/11 in northern BC. To remedy the effect of depression, lifestyle intervention approaches have been previously implemented and evaluated for their effectiveness $^{24,37}$. In Canada, reviews of employer directories identified some organizations with apparently successful and replicable initiatives for comprehensive WHP for mental health ${ }^{27}$. In a recent report, based on a national survey, workplace challenges faced by employees with mental health issues are highlighted, and insight into how employers can best support employees was cited ${ }^{57}$. In partial recognition of the impact resource sectors can have on rural and northern communities, large federally funded research initiatives have been launched with aims to build research capacity to enhance understanding of the social dimensions of rural and northern health in order to improve the health of residents living in these regions ${ }^{50}$.

Irrespective of such developments, many resource industry communities in northern $\mathrm{BC}$ have demonstrated historic economic vulnerability, demographic instability, and negative health impacts, stemming from declining and/or boom-bust economic and employment conditions ${ }^{51}$. For example, prevalence rates for acute CVD and mental disorders have been seen to rise during periods of economic decline and bust conditions in mining communities as compared to steady periods of mining employment. This is not observed in other resource-based communities ${ }^{51}$. The current paper focuses on $\mathrm{T} 2 \mathrm{D}$, not to negate other common disease conditions noted in northern $\mathrm{BC}$, but because $\mathrm{T} 2 \mathrm{D}$ interventions in the workplace are lacking and we believe, as literature has identified, that a WHP focus on T2D will help to also treat and improve mental conditions such as depression, and try to keep people away from illicit drug use.

\subsection{Built Environment and Workplace Health}

Other efforts on which progress has been made include the built environment, which promotes and has impact on both healthy eating and active living, alongside health and social policies that influence food marketing ${ }^{23,43}$. An environment that provides convenient access to walking paths, local shops and health-related stores promotes lower levels of obesity ${ }^{54}$. In the Canadian context, remote or northern communities, especially those with significant Aboriginal populations, are challenged by a lack of access to affordable nutritious foods, due to high transport costs limiting dietary choice ${ }^{43}$. The lack of local and convenient destinations with healthy food stores within walking distance results in an over-reliance on vehicles for transportation to other destinations ${ }^{43}$. To mitigate the effect of chronic diseases on employee productivity and decrease health care costs, employers are increasingly implementing public health strategies that include comprehensive workplace health promotion efforts with environmental policy supports ${ }^{10,23}$.

\subsection{Suitability of the Workplace to Implementation of Health Promotion Interventions}

The workplace is recognized internationally as a suitable setting for health promotion ${ }^{46,61}$. The workplace offers a natural, convenient and socially ideal environment and infrastructure to support the promotion of the health and wellness of a cohort of workers ${ }^{60}$. Individuals who work full-time spend more of their waking hours at work than in their homes ${ }^{21}$. The workplace setting can therefore be harnessed to offer workers frequent and sustained exposure to effective interventions during prime hours ${ }^{41}$. Workers congregate; they have a participatory group consciousness; and health information can be centrally communicated ${ }^{19}$. The workplace also offers the opportunity to utilize employer incentives $^{29}$, as employers can affect health behaviours through increasing the availability of and opportunities for physical activity, or through the provision of social support and fostering of social norms of healthy behaviour ${ }^{23}$. In underserviced and remote areas, the workplace also has the potential for increased access to populations that may be difficult to engage in other settings outside of work ${ }^{23,29}$.

\subsection{Workplace Health Promotion; the Need for a Conceptual Framework}

The WHO defines a healthy workplace as: "One in which workers and managers collaborate to use a continual improvement process to protect and promote the health, safety and well-being of workers and the sustainability of the workplace" ${ }^{\prime 1}$. Further the definition includes qualifiers that must be taken into consideration, including, for example, health and safety concerns in the physical work environment and the psychosocial work environment. Workplace Health Promotion (WHP) thus gives workers power to exercise control over the improvement of their health ${ }^{11}$. This is achieved in a reciprocal and shared manner through promoting the active participation of employees in health activities and encouraging personal development in the background of an improved work organization and environment ${ }^{46}$, as well as through transparent evaluation of effectiveness of initiatives employed using a best practice approach $^{12}$.

\subsection{The Importance of WHP for Workers}

Implementation of WHP is important because the entitlement to a safe and healthy work environment is a 
fundamental human right ${ }^{11}$. Effective WHP programs address organizational conditions, benefit employers, and promote healthy behaviours not only for individuals but also for all workers. Changes in health behaviour in a single domain also become generalized $^{19,33}$. Hence, achieving a healthy workforce results in improved health for individuals and society ${ }^{60}$. The overall benefits of implementing interventions targeting nutrition and physical activity in workplaces in an effort to improve the diet and lifestyle of employees, and therefore, reduce the incidence of illness are well-documented ${ }^{21,61}$. Promoting workplace health through employee wellness and safety programs would be an excellent opportunity for workers. The overall benefits of improvements to dietary intakes and of being physically active on a regular basis through the workplace can include: reducing body fat and body weight; high levels of health-related fitness; improved cognition/memory, self-confidence, reduction in work-related stress, accidents and injuries, work-related illnesses, job dissatisfaction, burnout, absenteeism, and disability ${ }^{11,23}$. Those who adhere to healthy eating patterns and remain physically active tend to have low risk profiles for the development of numerous medical chronic conditions. The benefits for those who engage in physical activity are paramount; including enhanced glucose metabolism and lower rates of T2D, depression, and all-cause mortality than their inactive counterparts $^{21,41}$. When a comprehensive WHP is implemented, employees are motivated and empowered to care for themselves. Effective interventions do not only benefit employees, they may also lead to secondary improvements in the lifestyles of their families ${ }^{40}$.

\subsection{Importance of WHP for Employers}

According to Prank and Kottke ${ }^{41}$, employers are well positioned to initiate and influence health policy initiatives designed to create supportive environments inside workplace. Studies report that in the long term, a company's success and ability to compete depends not only on good safety records, but also on having healthy and satisfied workers ${ }^{11,15}$. Improved employee health outcomes resulting from effective WHP interventions on physical activity and nutrition can be advantageous for the employer. For example, potential benefits could include: a drop in absenteeism and sick leave ${ }^{7,21}$; increased on-the-job productivity in terms of quality and quantity of product or customer service ${ }^{15}$; and reduced costs of work-related morbidity and mortality. For the employer, a healthier workforce also translates to reduced disability, workers' compensation or union grievance costs, and ultimately improved company reputation and success which can result in long-term economic prosperity and stability not only for the company, but also for individuals and their communities. These employer benefits should be enough evidence to justify investments to pursue WHP initiatives.

\subsection{Review of Effectiveness of WHP Interventions}

Among the effective workplace interventions were multi-component approaches that include: a combination of educational and environmental components (access to

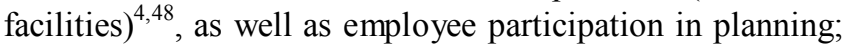
point-of-decision prompts to engage in physical activity (for example, signage encouraging employees to take the stairs instead of the elevator $)^{55,63}$; workplace employee/employer advisory boards/committees in planning and implementing workplace physical activity interventions; use of pedometers to help increase physical activity participation; access to, and opportunities for, subsidized healthier foods in the workplace; and, emphasis on improving eating behaviours ${ }^{2,63}$.

A combination of individual and organizational approaches to occupational stress is the most effective and important success factors are participation of employees in planning, implementation and evaluation of changes, and the role of management in supporting employees through effective communication ${ }^{11}$.Workplace health promotion (WHP) programs targeting physical inactivity and diet behaviours can be effective in improving health-related chronic conditions such as obesity, diabetes and cardiovascular risk (CV) factors through increasing participation rates by using a dynamic and engaging participatory process to involve workers and their representatives in the preparation and implementation of the measures. A comprehensive program to increase physical activity that includes individual counseling, health promotion education and fitness facilities is more effective than single-focus programs. Individual and organizational approaches to improving nutrition that include point-of-purchase information and environmental supports can influence employee nutrition habits while at work ${ }^{11}$. A WHO review of interventions to improve diet and physical activity reported that multicomponent workplace interventions were effective, in that these interventions provide healthy food and beverages at the workplace; provide space for fitness or encourage stair use; involve the family; and provide individual behaviour-change strategies.

Workplace health promotion (WHP) policies and environmental approaches to physical activity identified in the literature include: allowing flexible work hours; encouraging breaks from prolonged sitting; adopting transport plans to encourage active transportation; providing subsidies and on-site facilities such as bike storage, showers, and lockers; offering reimbursement for recreation memberships; posting signage to take the stairs; and providing child care during after-hours ${ }^{23}$. It is important to recognize that all policy and environmental approaches may not be suitable for all workplaces as organizational size, sector, product, and workers' characteristics must be considered. It is important to note, however, that workplace interventions are successful in achieving small improvements in health behaviours in the short-term. Obesity interventions have demonstrated only modest challenges associated with altering health ${ }^{21}$. Although short-term 
changes in diet, physical activity and health are important, it is ultimately long-term changes that will reduce employees' risk for diabetes and cardiovascular disease ${ }^{29}$.

A meta-analysis conducted by Rogen and colleagues $^{21}$ noted that workplace health promotion (WHP) programs that have been conducted to date showed variation in study design, and methods used including population characteristics. To investigate the influence of specific population groups (for example, shift workers, and other men working in the resource-based industry sector such as trucking, logging, mining, and forestry workers), the type of program and interventions used, and overall study rigor and quality on the effectiveness of WHP programs is crucial ${ }^{21}$.

Many of the published studies investigating specifically the role of physical activity in the workplace are of poor methodological quality ${ }^{64}$. Given the increasing emphasis on the workplace as an ideal context (setting) for promoting the beneficial effects of physical activity on employee wellness, it is important to understand how effective any physical activity approach on employee health. This would include understanding the type, frequency, duration, and intensity of the physical activity measurement or approach used.

\subsection{Gaps in WHP Programs}

The literature on WHP programs/studies reveals a number of gaps that include lack of: adequate follow-up and assessment of long term intervention effectiveness (especially with respect to factors that influence/facilitate sustained changes in behaviour); knowledge of the practical and logistical issues around provision of healthy foods in the workplace; knowledge of the most rigorous and feasible ways to assess the effectiveness of policy and environmental interventions to increase physical activity participation and healthy eating in workplace ${ }^{44}$. Evidence also reveals that transportation policy in relation to opportunities and participation in physical activity ${ }^{28}$, and long-term effects of interventions based on the use of environmental prompts to increase the use of stairs in workplace settings, are specific policy and environmental interventions needing further study².

\section{Conclusions and Recommendations}

The effectiveness of workplace health promotion programs in intervention studies depends on several factors including the study population, study design and methodological rigor. A recent meta-analysis of 21

RCT-based workplace health promotion programs has been published. While this systematic review provides detailed account of individual studies that implemented physical activity and workplace health interventions, the overall effect size was very small in regards to overall effectiveness of such interventions, and their implication for health policy.

Such small effects are not surprising given the heterogeneity of study samples and the contexts or settings in which the populations were studied ${ }^{47}$.

The current paper proposes to adapt the WHO Model and Framework by Burton ${ }^{11}$ for implementation of WHP interventions related to T2Dprevention and management in Men working in the resource industry in northern BC. The WHO model aims to embrace a workplace setting in which employers consistently and effectively protect, promote, and support a complete profile of health status encompassing physical, mental and psycho-social well-being of workers. The ultimate goal of the WHO Model is to influence employees' health status and sustain efficiency and productivity within a given organization. The WHO graphical model depicts workers' health needs and preferences in relation to health resources, and physical and psychosocial work environment, taking into consideration building capacity with community engagement and support.

To successfully create such a healthy workplace, the WHO recommends employers follow cyclic or iterative process that involves continually planning, acting, reviewing and improving on the activities of the program, while adhering to the core principles of leadership engagement based on core values of ethics and worker involvement ${ }^{34}$. The model also encourages the prioritization of needs not only through the opinions and preferences of the workers and employers, but also through the position on Maslow's hierarchy of needs ${ }^{38}$, in which it is important to first deal with problems related to physical safety and health as they are more basic and immediately threatening than those concerned with mental health and well-being, and self-esteem needs.

\section{REFERENCES}

[1] Allender S, Gleeson E, Crammond B, Sacks G, Lawrence M, Peeters A, et al. Policy change to create supportive environments for physical activity and healthy eating: which options are the most realistic for local government? Health Promotion International 2012;27(2):261-274.

[2] Allison KR, Dwyer JM, MacGillivray A, Hawrychuk S. A review of workplace and community interventions for adults: effects of physical activity, eating behaviours and BMI - risk factors for diabetes. [Internet]. Ontario Agency for Health Protection and Promotion; 2011 [cited 2012 Nov 16]. Available from:

http://www.oahpp.ca/services/documents/hpcdip/Diabetes\% 20Lit\%20Review\%20-\%20Sept\%202011a.pdf

[3] Bingham SB. Minding Our Bodies, Physical Activity for Mental Health: Literature Review. [Internet]. Canadian Mental Health Association; 2009 [cited 2012 Oct 6]. Available from:

http://www.mindingourbodies.ca/sites/default/files/mob_liter ature_review_0.pdf

[4] British Columbia Ministry of Health. Evidence review: Healthy living - physical activity \& healthy eating. [Internet]. Ministry of Health, Population Health and Wellness. Victoria, British Columbia; 2006 [cited 2012 Nov 2]. Available from: http://www.health.gov.bc.ca/public-health/pdf/Healthy_Livi ng_Physical_Activity_Healthy_Eating_Evidence_Review.pd 
f

[5] British Columbia Coroners Services. Accidental Workplace Deaths 2005-2010 YTD. Special request for Northern Health. November 2010. Ministry of Public Safety and Solicitor General: Northern Region. Northern Health; 2010.

[6] Bowering D. Where are the men? Chief Medical Health Officer's Report on the Health and Wellbeing of Men and Boys in Northern British Columbia. [Internet]. Northern Health; 2011 [cited 2012 Oct 20]. Available from: http://men.northernhealth.ca/Portals/4/pdfs/mens-health-repo rt-web-nov11.pdf

[7] Brown HE, Gilson ND, Burton NW, Brown WJ. Does physical activity impact on presenteeism and other indicators of workplace well-being? Sports Medicine 2011;41(3):249-262.

[8] Bruehl H, Wolf OT, Convit A. A blunted cortisol awakening response and hippocampal atrophy in type 2 diabetes mellitus. Psychoneuroendocrinology 2009;34(6):815-821.

[9] Brummett BH, Boyle SH, Ortel TL, Becker RC, Siegler IC, Williams RB. Associations of depressive symptoms, trait hostility, and gender with C-reactive protein and interleukin-6 response following emotion recall. Psychosomatic Medicine 2010;72(6):333-339.

[10] Buchberger B, Heymann R, Huppertz H, Friepörtner K, Pomorin N, Wasem J. The effectiveness of interventions in workplace health promotion as to maintain the working capacity of health care personal. GMS Health Technology Assessment [Internet]. 2011 Sep 28 [cited 2012 Dec 28];7. Available http://www.ncbi.nlm.nih.gov/pmc/articles/PMC3198117/

[11] Burton J. WHO Healthy Workplace Framework and Model: Background Document and Supporting Literature and Practices. [Internet]. World Health Organization. Geneva, Switzerland; 2010 [cited 2012 Oct 19]. Available from: http://www.who.int/occupational health/healthy workplace framework.pdf

[12] Canadian Diabetes Association. Best and Promising Practices in Diabetes Education. [Internet]. Canadian Diabetes Association; 2010 [cited 2012 Dec 5]. Available from: http://www.diabetes.ca/documents/for-professionals/Bestpra ctice-eng.pdf

[13] Canadian Diabetes Association. Diabetes: At the tipping point: Diabetes in British Columbia. [Internet]. Canadian Diabetes Association; 2011 [cited 2012 Oct 19]. Available from:

http://www.diabetes.ca/advocacy/reports-and-information/di abetes-canada-at-the-tipping-point/

[14] Canadian Diabetes Association. Diabetes: Canada at the Tipping Point - Charting a New Path [Internet]. Diabetes Quebec. 2011 [cited 2012 Dec 29]. Available from: http://www.diabete.qc.ca/en/html/activities/repport 2011.ht $\mathrm{ml}$

[15] Cancelliere C, Cassidy JD, Ammendolia C, Côté P. Are workplace health promotion programs effective at improving presenteeism in workers? A systematic review and best evidence synthesis of the literature. BMC Public Health 2011;11(1):395.

[16] Centers for Disease Control and Prevention. Workplace Health Promotion: Physical Activity [Internet]. 2011 [cited
2012 Dec 29]. Available from: http://www.cdc.gov/workplacehealthpromotion/implementat ion/topics/physical-activity.html

[17] Champaneri S, Wand GS, Malhotra SS, Casagrande SS, Golden SH. Biological basis of depression in adults with diabetes. Current Diabetes Reports2010;10(6):396-405.

[18] Chau JY, Der Ploeg HP van, Van Uffelen JGZ, Wong J, Riphagen I, Healy GN, et al. Are workplace interventions to reduce sitting effective? A systematic review. Preventive Medicine 2010;51(5):352-356.

[19] Cherniack M, Lahiri S. Barriers to implementation of workplace health interventions: An economic perspective. Journal of Occupational and Environmental Medicine2010; 52(9): 934-942.

[20] Colley RC, Garriguet D, Janssen I, Craig CL, Clarke J, Tremblay MS. Physical activity of Canadian adults: accelerometer results from the 2007 to 2009 Canadian Health Measures Survey. Health Reports 2011;22(1):7-14.

[21] Conn VS, Hafdahl AR, Cooper PS, Brown LM, Lusk SL. Meta-analysis of workplace physical activity interventions. American Journal of Preventive Medicine2009;37(4):330-339.

[22] Curry J. Northern British Columbia Community-Based Research Needs. Western Geography, 8/9 [1998/99], pp. 1-23. [Internet]. Canadian Association of Geographers; 1999 [cited 2012 Oct 25]. Available from: http://www.geog.uvic.ca/dept/wcag/curry.pdf

[23] Curry R. Workplace Physical Activity: A Review of Literature Examining Policy and Environmental Approaches. [Internet]. Activity-Friendly Communities Component Group; 2012 [cited 2012 Nov 15]. Available from: http://www.hamilton.ca/NR/rdonlyres/79F8F671-B240-4B9 F-99EB-3DE3901D58BD/0/Literature review FINAL.pdf

[24] De Groot M, Doyle T, Kushnick M, Shubrook J, Merrill J, Rabideau E, et al. Can lifestyle interventions do more than reduce diabetes risk? Treating depression in adults with type 2 diabetes with exercise and cognitive behavioral therapy. Current Diabetes Reports 2012; 12(2):157-166.

[25] Elovainio M, Aalto A-M, Kivimäki M, Pirkola S, Sundvall J, Lönnqvist J, et al. Depression and C-reactive protein: population-based Health 2000 Study. Psychosomatic Medicine 2009;71(4):423-430.

[26] Evans J, Frank B, Oliffe JL, Gregory D. Health, Illness, Men and Masculinities [HIMM]: a theoretical framework for understanding men and their health. Journal of Men's Health2011;8(1):7-15.

[27] Fields W. Workplace Health Promotion; Research Snapshot. [Internet]. Canadian Mental Health Association, Ontario. 2009 [cited 2012 Dec 29]. Available from: http://www.ontario.cmha.ca/network_story.asp?cID=121256

[28] Hosking J, Macmillan A, Connor J, Bullen C, Ameratunga S. Organizational travel plans for improving health [Internet]. Cochrane Database of Systematic Reviews. 2010 [cited 2012 Dec 30]. Available from: http://onlinelibrary.wiley.com/doi/10.1002/14651858.CD005 575.pub3/abstract

[29] Hutchinson AD, Wilson C. Improving nutrition and physical activity in the workplace: a meta-analysis of intervention 
studies. Health Promotion International 2012;27(2):238-249.

[30] Katzmarzyk PT, Church TS, Craig CL, Bouchard C. Sitting time and mortality from all causes, cardiovascular disease, and cancer. Medicine and Science in Sports and Exercise2009;41(5):998-1005.

[31] Klein BEK, Klein R, Lee KE. Components of the Metabolic Syndrome and Risk of Cardiovascular Disease and Diabetes in Beaver Dam. Diabetes Care2002;25(10):1790-1794.

[32] Kirsten W. Making the link between health and productivity at the workplace -- a global perspective. Industrial Health 2010;48(3):251-255

[33] Laing S, Hannon P, Talburt A, Kimpe S, Williams B, Harris J. Increasing Evidence-Based Workplace Health Promotion Best Practices in Small and Low-Wage Companies, Mason County, Washington, 2009. Preventing Chronic Disease [Internet]. 2012 Apr [cited 2012 Dec 28]; Available from: http://www.cdc.gov/pcd/issues/2012/11_0186.htm

[34] Lewchuk W, Robb AL, Walters V. The Effectiveness of Bill-70 and Joint Health and Safety Committees in Reducing Injuries in the Workplace: The Case of Ontario. Canadian Public Policy / Analyse de Politiques 1996 Sep;22(3):225.

[35] Lin EHB, Rutter CM, Katon W, Heckbert SR, Ciechanowski $\mathrm{P}$, Oliver MM, et al. Depression and advanced complications of diabetes: a prospective cohort study. Diabetes Care2010 Feb;33(2):264-269.

[36] Lucini D, Solaro N, Lesma A, Gillet VB, Pagani M. Health promotion in the workplace: assessing stress and lifestyle with an intranet tool. Journal of Medical and Internet Research2011;13(4):e88.

[37] Martin A, Sanderson K, Cocker F. Meta-analysis of the effects of health promotion intervention in the workplace on depression and anxiety symptoms. Scandinavian Journal of Work, Environment \& Health2009;35(1):7-18.

[38] Maslow HA. A theory of human motivation. Psychological Review. 1943;50(4):370-396.

[39] Mezuk B, Eaton WW, Albrecht S, Golden SH. Depression and type 2 diabetes over the lifespan: a meta-analysis. Diabetes Care2008;31(12):2383-2390.

[40] Plotnikoff RC. Physical Activity in the Management of Diabetes: Population-based Perspectives and Strategies. Canadian Journal of Diabetes 2006;30(1):52-62.

[41] Pronk NP, Kottke TE. Physical activity promotion as a strategic corporate priority to improve worker health and business performance. Preventive

Medicine2009;49(4):316-321.

[42] Public Health Agency of Canada. Report from the National Diabetes Surveillance System: Diabetes in Canada, 2008 [Internet]. 2008 [cited 2012 Dec 29]. Available from: http://www.phac-aspc.gc.ca/publicat/2008/ndssdic-snsddac-0 $8 /$

[43] Public Health Agency of Canada. Diabetes in Canada: Facts and figures from a public health perspective. Chapter $4-$ Reducing the risk of type 2 diabetes and its complications. [Internet]. 2011 [cited 2012 Dec 29]. Available from: http://www.phac-aspc.gc.ca/cd-mc/publications/diabetes-dia bete/facts-figures-faits-chiffres-2011/highlights-saillants-eng .php
[44] Ramanathan S, Allison KR, Faulkner G, Dwyer JJM. Challenges in assessing the implementation and effectiveness of physical activity and nutrition policy interventions as natural experiments. Health Promotion International 2008;23(3):290-297.

[45] Robroek SJ, Van Lenthe FJ, Van Empelen P, Burdorf A. Determinants of participation in worksite health promotion programmes: a systematic review. International Journal of Behavioural Nutrition and Physical Activity 2009; 20(6):26.

[46] Robroek SJW, Van de Vathorst S, Hilhorst MT, Burdorf A. Moral issues in workplace health promotion. International Archives of Occupational and Environmental Health 2012;85(3):327-331.

[47] Rongen A, Robroek SJW, van Lenthe FJ, Burdorf A. Workplace Health Promotion: A Meta-Analysis of Effectiveness. American Journal of Preventive Medicine2013;44(4):406-415.

[48] Sallis JF, Glanz K. Physical activity and food environments: solutions to the obesity epidemic. Milbank Quarterly 2009; 87(1):123-154.

[49] Searle A, Calnan M, Lewis G, Campbell J, Taylor A, Turner K. Patients' views of physical activity as treatment for depression: a qualitative study. British Journal of General Practice2011; 61(585):149-156.

[50] Shandro J, Koehoorn M, Scoble M, Ostry A, Gibson N, Veiga M. Mental Health, Cardiovascular Disease and Declining Economies in British Columbia Mining Communities. Minerals 2011;1(1):30-48.

[51] Shandro JA, Veiga MM, Shoveller J, Scoble M, Koehoorn M. Perspectives on community health issues and the mining boom-bust cycle. Resources Policy 2011;36(2):178-186.

[52] Shubair MM, Gagne AL. Men's health in northern British Columbia: analysis and reporting of early intervention screening program data related to cardiovascular health. Global Journal of Health Science2012; 4(4):90-106.

[53] Simen-Kapeu A, Veugelers PJ. Socio-economic gradients in health behaviours and overweight among children in distinct economic settings. Canadian Journal of Public Health 2010; 101 (Suppl 3):S32-S36.

[54] Stafford M, Cummins S, Ellaway A, Sacker A, Wiggins RD, Macintyre S. Pathways to obesity: identifying local, modifiable determinants of physical activity and diet. Social Science and Medicine 2007;65(9):1882-1897.

[55] Soler RE, Leeks KD, Buchanan LR, Brownson RC, Heath GW, Hopkins DH. Point-of-decision prompts to increase stair use. A systematic review update. American Journal of Preventive Medicine 2010;38 (Suppl 2):S292-S300.

[56] Tamers SL, Beresford SAA, Cheadle AD, Zheng Y, Bishop SK, Thompson B. The association between worksite social support, diet, physical activity and body mass index. Preventive Medicine 2011;53(1-2):53-56.

[57] Thorpe K, Chenier L. Building Mentally Healthy Workplaces: Perspectives of Canadian Workers and Front-Line Managers [Internet]. The Conference Board of Canada. 2011 [cited 2012 Dec 29]. Available from: http://www.conferenceboard.ca/e-Library/abstract.aspx?did= 4287.

[58] Waters LA, Galichet B, Owen N, Eakin E. Who participates 
in physical activity intervention trials? Journal of Physical Activity and Health2011;8(1):85-103.

[59] White A. Men's Health in the 21st Century. International Journal of Men's Health 2006;5(1):1-17.

[60] Wierenga D, Engbers LH, Empelen P van, Hildebrandt VH, Mechelen $\mathrm{W}$ van. The design of a real-time formative evaluation of the implementation process of lifestyle interventions at two worksites using a 7-step strategy [BRAVO@Work]. BMC Public Health 2012;12(1):619.

[61] Wong JYL, Gilson ND, Van Uffelen JGZ, Brown WJ. The effects of workplace physical activity interventions in men: a systematic review. American Journal of Men's Health
2012;6(4):303-313.

[62] World Health Organization. 10 facts on physical activity [Internet]. WHO 2011 [cited 2012 Dec 29]. Available from: http://www.who.int/features/factfiles/physical_activity/en/

[63] World Health Organization. Interventions on Diet and Physical Activity: What Works [Internet]. WHO 2009 [cited 2012 Dec 30]. Available from: http://www.who.int/dietphysicalactivity/whatworks/en/.

[64] Malik SH, Blake H, Suggs S. A systematic review of workplace health promotion interventions for increasing physical activity. British Journal of Health Psychology 2014;19:149-180. 